\title{
Operation of the Grand Ethiopian Renaissance Dam: Potential Risks and Mitigation Measures
}

\author{
Nourhan Abdelazim, Hesham Bekhit and Mohamed Nasr Allam
}

Cairo University, Cairo, Egypt.

\begin{abstract}
Several studies have simulated the Grand Ethiopian Renaissance Dam filling and operation but the optimum operation policy of the dam has not been fully investigated. This study presents a nonlinear optimization model for the operation of the Grand Ethiopian Renaissance Dam using natural historical inflow time series data (1912-2011) with an objective function that maximizes firm energy. The model results show that the mean hydropower production of the dam is about $14650 \mathrm{GWh} / \mathrm{y}$. The firm energy is found to be in the order of $12900 \mathrm{GWh} / \mathrm{y}$, which represents about $24.5 \%$ of dam installed hydropower capacity. It was found that the Grand Ethiopian Renaissance Dam operation, if used only for power production, will permanently reduce the Blue Nile flow to downstream countries by an average of $3.2 \%$. It will also extend the downstream drought periods by $200 \%-300 \%$ compared to the time before dam construction. In order to ensure better downstream conditions, smaller dam active storage capacities were modeled and the results were analyzed. As a substantial mitigation measure, decreasing GERD live storage by $40 \%$ to reach $35 \mathrm{~km}^{3}$ yields $90 \%$ of the mean annual hydropower production of the announced design while better preserving the downstream water rights and conditions.
\end{abstract}

\section{Introduction}

The Nile is an international river in northeastern Africa. Its basin is the most highly populated African river basin. It shares its water resources between eleven countries: Tanzania, Uganda, Rwanda, Burundi, Democratic Republic of the Congo, Kenya, Ethiopia, Eritrea, South Sudan, Sudan and Egypt. The Nile originates in two distinct geographical and hydrological plateaus: the Ethiopian Plateau and the Equatorial Lakes Plateau. The Atbara, Sobat and Blue Nile rivers originate in the Ethiopian Plateau, which contributes about $85 \%$ of river flow measured at Aswan, in the south of Egypt. The Ethiopian Plateau is characterized by its high monthly and annual flow seasonality. The remaining 15\% comes from a less fluctuating river, the White Nile, that originates in the equatorial lakes. The main Nile starts where the Blue Nile and White Nile meet near Khartoum, Sudan and then it flows through Egypt. The Nile extends from latitude $4^{\circ} \mathrm{S}$ to $35^{\circ} \mathrm{N}$.

The Nile Basin rainfall distribution is highly uneven both spatially and seasonally; precipitation declines downstream until the river reaches the arid and desert conditions of Egypt (Shahin 1985). Runoff producing areas are mainly limited to the Ethiopian Highlands and the Equatorial Lakes Plateau, with minor contributions from western South Sudan. Evapotranspiration (ET) is a major component of the Nile Basin water balance, and accounts for $\sim 87 \%$ of rainfall. Thus the Nile runoff coefficient is $\sim 3.9 \%$, which is relatively small. It is obvious that the arid regions of Egypt and Sudan have greater potential ET than the humid headwaters of the Nile. However, the actual ET decreases moving downstream due to the limited availability of water and little vegetation. Egypt is a dry country; the Nile provides Egypt with $97 \%$ of its water requirements. The Blue Nile contribution to the Nile flow plays a significant role in Egyptian water security. It contributes $~ 60 \%$ of the net average natural flow of the Nile measured at Aswan. The average annual runoff of the Blue Nile at Roseries, near the Ethiopia-Sudan border, is $50 \mathrm{~km}^{3}$. The Blue Nile rainfall is highly seasonal and mainly falls during the summer monsoon season. Within Sudan, the Blue Nile tributaries, mainly the Rahad and Dinder rivers, augment the annual river flow to about $54 \mathrm{~km}^{3}$. Ethiopia started constructing the Grand Ethiopian Renaissance Dam (GERD) across the Blue Nile in 2011, which is tens of kilometers away from the Sudan border. It was recently announced in September 2019 by Ethiopian Electric Power (EEP) that the entire project is $68 \%$ complete. The absence of complete impact studies on the downstream countries necessary for reaching agreement on dam size, filling and operation threatens the water security, national economy and stability of Egypt, the most downstream country.

The most detailed report that carefully examined all the available studies of GERD is the report of International Panel of Experts (IPoE). The IPoE was from representatives of the three countries (Egypt, Ethiopia, and Sudan) and four international independent experts to "review the design documents of the GERD, provide transparent information sharing and to solicit understanding of the benefits and costs accrued to the three countries

Abdelazim, Nourhan, Hesham Bekhit and Mohamed Nasr Allam. 2020. "Operation of the Grand Ethiopian Renaissance Dam: Potential Risks and Mitigation Measures." Journal of Water Management Modeling 27: C469. doi: 10.14796/JWMM.C469.

(C) CHI 2020. www.chijournal.org ISSN 2292-6062. 
and impacts of the GERD" (IPoE 2013). The main conclusion of their final report was that the GERD project began on the basis of piecemeal preliminary studies and design documents, with only a very basic analysis of how the project would affect downstream neighbors. The IPoE report further stated that several potential positive benefits for downstream countries were reported in the initial studies of the dam, such as decreased sedimentation and a reduction in flooding. However, the main conclusion of the report was that "these potential benefits are not all quantified and confirmed" (IPoE 2013). Van Der Krogt and Ogink (2013) used the Eastern Nile Water Simulation Model (ENWSM) to evaluate the impacts of GERD. The model covers $103 \mathrm{y}$ of historical climatic records of the Nile Basin. The results showed that GERD would flatten out the Blue Nile natural flow regime, which would eliminate the shortages in Sudanese irrigation abstractions during the winter and increase Sudan hydropower production by $18 \%$. It was found that Lake Nasser inflow would be reduced by $\sim 10 \%$ and High Aswan Dam (HAD) power production by $28 \%$. Mulat and Moges (2014) simulated GERD impacts on HAD using a MIKE basin model. They examined a 6 y impounding period with the same historical average flow, and assuming no drought found that GERD would generate $6145 \mathrm{GWh} / \mathrm{y}$. The results showed reductions of $26 \%$ in HAD inflow and $12 \%$ in HAD hydropower during the filling phase in addition to a $\sim 7 \%$ reduction in HAD hydropower production during GERD operation. From simulation of $50 \mathrm{y}$ of Blue Nile inflows, Geressu and Harou (2015) found that multiple reservoirs of smaller sizes are much better for river system performance, stating "It would be advantageous to build a combination of reservoirs rather than a single reservoir with equivalent storage size." Habteyes et al. (2015) formulated an empirical hydro-economic model using the general algebraic modeling system (GAMS) to maximize the total water use benefits of GERD for all parties. A Pareto improvement in water use is achieved by constraining GERD filling to be only from reduced Ethiopian irrigation use of Nile water while maintaining downstream water rights. Thus average GERD storage was only $20 \%$ of the design capacity, producing $\sim 75 \%$ of the predicted hydropower production without negative impacts on HAD storage. Hussein (2015) also conducted GERD simulation using MATLAB software which considered changing climate. Time series analysis was used to generate flow time series at GERD and the remaining river inflow sources (1000 cases, 30 y each). The study indicated that HAD will take $\sim 30$ y of recovery after initial GERD reservoir filling. Senosy (2015) carried out a stochastic analysis of GERD impacts on HAD using the GERD-HAD simulation model. The model was used to generate 100 inflow series, each having a 100 y span and a $10 \mathrm{~d}$ timestep. Based on the Ethiopian Electric Power Corporation (EEPCo) filling and operational rules, the results show $12300 \mathrm{GWh} / \mathrm{y}$ GERD clean energy production, $5.1 \mathrm{~km}^{3}$ average $\mathrm{HAD}$ yearly inflow deficit and $34 \% \mathrm{HAD}$ power reduction. It was also found that a smaller dam size of $14 \mathrm{~km}^{3}$ can generate $\sim 70 \%$ of the energy generated by GERD at planned size.

The cited studies and many others simulated GERD operation using many techniques but until now the optimum operational GERD policy has not been thoroughly investigated through optimization schemes to better reach a win-win situation for all parties. We developed an optimization model for GERD operation and investigated the associated impacts of GERD on the Eastern Nile system. The model is used for different storage scenarios to examine the impact of dam capacity and its operation on Ethiopian hydropower and on water resources in the downstream countries. The data used in this research was collected and validated from various sources including the Ministry of Water Resources and Irrigation (MWRI 2014), the IPoE and EEPCo reports, and the Nile Basin Initiative (NBI 2016).

\section{GERD Description}

GERD is located $\sim 15 \mathrm{~km}$ east of the border between Sudan and Ethiopia. GERD was designed as a roller compacted concrete dam, $155 \mathrm{~m}$ high with $74 \mathrm{~km}^{3}$ storage capacity and $6000 \mathrm{MW}$ installed turbines capacity. The dam has three spillways and one low level outlet and is associated with a saddle dam. The saddle dam is $50 \mathrm{~m}$ high, $5 \mathrm{~km}$ long and retains $90 \%$ of GERD active storage. GERD, with its design storage capacity, would control 1.5 times the mean annual flow of the Blue Nile.

Figure 1 shows a typical cross section of GERD. The upstream ground level of the dam is $500 \mathrm{~m}$. GERD will release the water from turbines if its reservoir water level $>590 \mathrm{~m}$. In case of droughts, GERD may use the low level outlets to release the water. During high floods, water may be released through any of the three spillways only if the reservoir water level exceeds the spillway crest level. The diversion outlets are used as a diversion facility during the construction of the dam. The relationship between the reservoir water level, reservoir volume and reservoir area was used in the mathematical model.

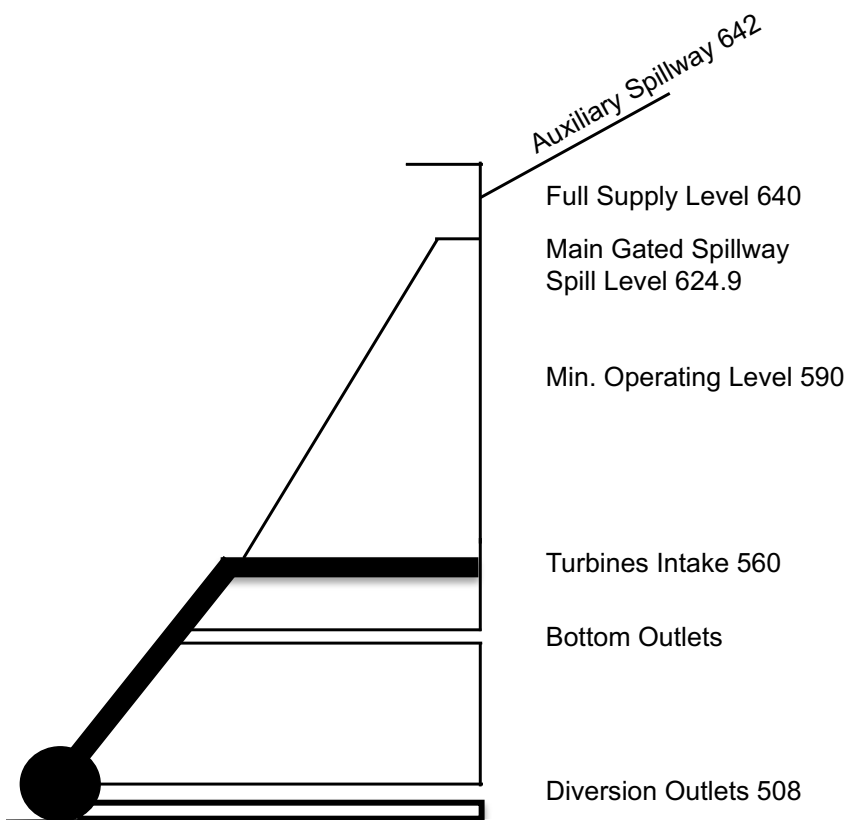

Figure 1 Typical GERD cross-section. 
The main dam body of GERD has two powerhouses. The right powerhouse has 10 Francis turbines with $3750 \mathrm{MW}$ total installed capacity, while the left powerhouse has 6 Francis turbines with $2250 \mathrm{MW}$ installed capacity. Each turbine has $270 \mathrm{~m}^{3} / \mathrm{s}$ flow capacity. According to EEPCo, turbine efficiency is assumed to be $95 \%$, in addition to $2 \%$ head losses $(\varepsilon=0.95 \times 0.98)$.

The historical monthly inflow time series at Deim station for 1912-2011 was used (Abdelazim 2017); the dataset statistics are shown in Table 1. Deim is a flow measurement station located on the Blue Nile just downstream of the Ethiopia-Sudan border. The optimization model was developed using extended Lingo 17.0 software, described on the company's website at lindo.com. The model timestep was adjusted to match the inflow data, which have a monthly timestep.

Table 1 Deim station monthly inflow statistics (1912-2011) in $\mathrm{km}^{3}$.

\begin{tabular}{cccc}
\hline Mean & Standard deviation & Max & Min \\
\hline 4.0821 & 5.0173 & 24.847 & 0.107 \\
\hline
\end{tabular}

\section{Mathematical Model}

\subsection{Constraints}

The Lingo non-negativity option was enabled for all model parameters and variables, which can take any real value from zero to positive infinity unless an upper limit is specified, as in some of the model constraints.

The water balance constraint, by which the storage at each timestep equals the storage at the previous timestep plus inflow minus outflow through different outlet options, system losses and abstractions, if any, is:

$$
S_{i+1}=S_{i}+R_{i}-\left(Q_{i}+\sum_{j=1}^{3} \operatorname{Spill}_{i, j}+Q o_{i}\right) \cdot \frac{\Delta T}{10^{9}}-E_{i}-\text { Seep }_{i}-A b s t_{i} \text { (1) }
$$

where:

$$
\begin{aligned}
S_{i}= & \text { reservoir storage at time } i\left(\mathrm{~km}^{3}\right), \\
R_{i}= & \text { stationary inflow at time } i\left(\mathrm{~km}^{3}\right), \\
Q_{i}= & \text { turbines outflow at time } i\left(\mathrm{~m}^{3} / \mathrm{s}\right), \\
S_{\operatorname{Sill}}= & \text { spillway } j \text { discharge at time } i\left(\mathrm{~m}^{3} / \mathrm{s}\right), \\
Q o_{i}= & \text { low-level outlets discharge at time } i\left(\mathrm{~m}^{3} / \mathrm{s}\right), \\
\Delta T= & \text { timestep }(\mathrm{s}), \\
E_{i}= & \text { net evaporation at time } i\left(\mathrm{~km}^{3}\right), \\
\text { Seep }_{i}= & \text { seepage at time } i\left(\mathrm{~km}^{3}\right), \text { and } \\
\text { Abst }_{i}= & \text { blue Nile abstractions upstream of GERD at time } i \\
& \left(\mathrm{~km}^{3}\right) .
\end{aligned}
$$

The net evaporation losses were obtained as the multiplication products of the net monthly evaporation rate coefficients after allowance for effective rainfall and runoff and the actual surface area of the GERD reservoir at each timestep.
The turbine outflow constraint, that water can only release through turbines if reservoir water level exceeds the minimum operating level of turbines $(M O L=590 \mathrm{~m})$, is:

$$
Q_{i}\left\{\begin{array}{c}
\leq Q_{\max }, H_{i} \geq M O L \\
=0, \text { Otherwise }
\end{array}\right.
$$

where:

$Q_{\max }=$ turbine discharge maximum capacity $\left(\mathrm{m}^{3} / \mathrm{s}\right)$, and $H_{i}=$ water level of the reservoir at time $i(\mathrm{~m})$.

The spillways outflow constraint, where each of the GERD spillways operates only if reservoir water level exceeds the spillway crest level, is:

$$
\operatorname{Spill}_{i, j}=\left\{\begin{array}{c}
C_{j} B_{j}\left(H_{i}-C L_{j}\right)^{1.5}, H_{i} \geq C L_{j} \\
0, \text { Otherwise }
\end{array}\right.
$$

where:

$C_{j}=$ discharge coefficient of spillway $j$, and

$B_{j}, C L_{j}=$ spillway $j$ crest width and level $(\mathrm{m})$.

The low level outlets constraint, that water can pass through orifices during drought periods when the water level is below $M O L$ and above the orifices, is:

$$
Q o_{i}=\left\{\begin{array}{c}
C_{d} A_{o} \sqrt{2 g\left(H_{i}-C L_{o}\right)}, M O L_{o} \leq H_{i} \leq M O L \\
0, \text { Otherwise }
\end{array}\right.
$$

where:

$C_{d}=$ orifice discharge coefficient,

$A_{o}=$ orifice cross sectional area $\left(\mathrm{m}^{2}\right)$,

$g=$ acceleration of gravity $\left(\mathrm{m} / \mathrm{s}^{2}\right)$,

$C L_{0}=$ orifice level $(\mathrm{m})$, and

$M O L_{o}=$ orifice minimum allowable operating level $(\mathrm{m})$.

\subsection{Objective Function Scenarios}

The first scenario is maximization of the Ethiopian benefits through hydropower on one side, minimization of downstream risks by maximizing the release from the dam on the other side, and a weighted combination of both objectives:

$$
\max \sum_{i=1}^{n}\left|(w)\left[\frac{\varepsilon \gamma Q_{i}\left(H_{i}-T L\right)}{H P_{\max }}\right]+(1-w)\left[\frac{Q_{i}}{Q_{\max }}\right]\right|
$$

where:

$$
n=\text { number of timesteps (1200), }
$$

$w=$ weighting coefficient $(0-1)$,

$\varepsilon=$ hydropower plant efficiency,

$\gamma=$ specific weight of water $\left(9807 \mathrm{~N} / \mathrm{m}^{3}\right)$,

$T L=$ turbine level $(\mathrm{m})$, and

$H P_{\text {max }}=$ turbine hydropower installed capacity (W).

The second objective function (OF) scenario is to minimize the weighted sum of squared deficits of maximum upstream benefits of hydropower versus squared deficits of minimum downstream risks (maximum release): 


$$
\min \sum_{i=1}^{n}\left|(w)\left[1-\frac{\varepsilon \gamma Q_{i}\left(H_{i}-T L\right)}{H P_{\max }}\right]^{2}+(1-w)\left[1-\frac{Q_{i}}{Q_{\max }}\right]^{2}\right|
$$

The third OF is to minimize the weighted sum of the squared deficits of mean hydropower $\left(H P_{\text {mean }}\right)$ and the squared deficits of mean release $\left(Q_{\text {mean }}\right)$ :

$$
\min \sum_{i=1}^{n}\left|(w)\left[1-\frac{\varepsilon \gamma Q_{i}\left(H_{i}-T L\right)}{H P_{\text {mean }}}\right]^{2}+(1-w)\left[1-\frac{Q_{i}}{Q_{\text {mean }}}\right]^{2}\right|
$$

The last OF is to minimize the sum of the squared deviations of generated hydropower from GERD maximum firm energy $\left(F E_{k}\right)$ over the time series:

$$
\min \sum_{i=1}^{n}\left[\left(F E_{k}-\varepsilon \gamma Q_{i}\left(H_{i}-T L\right)\right)^{2}\right]
$$

Firm energy is defined as the generated energy to be minimally produced monthly for at least $90 \%$ of the time series for a given dam active storage capacity scenario $k$.

\subsection{GERD Operational Policy}

The operation rules of GERD have not yet been agreed upon and were assumed for this study. Ethiopia is building GERD to generate hydropower, which may be maximized by balancing between operating GERD at the maximum allowable water level while passing most of the outflow through the turbines. In order to achieve these operating conditions, we assumed that both the main gated spillway and the low-level outlets are closed during times of normal operation. The second assumption is that the model will not consider optimization during the impounding of the dam, which implies that the GERD reservoir is initially full. This means that downstream countries have already lost $74 \mathrm{~km}^{3}$ of Blue Nile water during the dam impounding phase in addition to the initial seepage losses. Thus downstream countries lose strategic storage and are subject to water shortages during impoundment. Seepage losses are not considered in the long term operation of the dam in this study. This study is limited to the impact of GERD operation on Ethiopian hydropower and the Blue Nile natural flow regime (GERD outflow); the impact is not propagated further to the operation of the dams downstream of GERD. Another important assumption is that no water is withdrawn or diverted for agriculture or other purposes at GERD, as the dam is assumed to operate only for power production.

\subsection{Performance Indicators}

In order to evaluate and compare the results of the operational model scenarios, five indicators are used.

Mean annual GERD hydropower production is:

$$
H P_{\text {mean }}=\frac{\sum_{1}^{N_{\text {years }}}\left[\sum_{1}^{12} \varepsilon \gamma Q_{i}\left(H_{i}-T L\right)\right]}{N_{\text {years }}}
$$

where: $\begin{aligned} N_{\text {years }}= & \text { number of years until the last year ending with } \\ & \text { almost the same initial water level. }\end{aligned}$

The plant factor, the ratio between the average HP generated and installed HP capacity, is:

$$
P F=H P_{\text {mean }} / H P_{\max }
$$

The mean annual Blue Nile flow deficit from the average historical flow due to GERD reservoir storage and operation is:

$$
\text { Deficit }_{\text {mean }}=\frac{\sum_{1}^{N_{\text {years }}}[\text { Annual inflow }- \text { Annual GERD outflow }]}{N_{\text {years }}}
$$

Firm energy for the $N_{\text {years }}$ of operation is:

Probability $\left[\varepsilon \gamma Q_{i}\left(H_{i}-T L\right) \geq F E\right]=0.90$

Drought is a prolonged period of below historical average Blue Nile flow. The ratio between the length of the extended drought period downstream of GERD and the longest historical natural drought is defined as $E D P_{\max }$.

\section{Results and Discussion}

\subsection{Evaluation of the Alternative Objective Func- tions}

The model results of using the four selected objective functions are evaluated. Almost $75 \%$ of the annual inflow comes in only four months, with a high standard deviation, as shown in Table 1. The first scenario (maximization of $H P$ and $Q$, Equation 5) failed to regulate GERD outflow, following the same natural inflow pattern, and thus causes frequent shutdowns and negligable firm energy since the model searches for the optimal (maximum) value of total HP production and outflow regardless of their distributions along the runtime. The second OF scenario (minimized deficit of $H P_{\max }$ and $Q_{\text {max }}$ Equation 6) showed results similar to the first scenario due to the high dam capacity as compared to the natural inflows. Different values of the weighting coefficient had no significant effect on regulating the natural flow regime for the first two scenarios. On the contrary, minimized variances of $H P$ and $Q$ (third scenario, Equation 7) better regulated the Blue Nile natural flow, while reducing HP by $\sim 15 \%$ compared to HP maximization. The $w$ values showed very close results under this operational scenario since flow regulation also regulates HP production and vice versa. However, the firm energy maximization OF (fourth scenario, Equation 8) better regulated GERD outflow and stabilized the dam firm energy with only $7 \%$ less hydropower than HP maximization. The firm energy $O F$ is regarded as the best relative to the other OFs, keeping in mind that its main drawback is in not considering the interest of the downstream countries, particularly during droughts. Table 2 summarizes the performance indicators of some model results using the different OFs. 
Table 2 Evaluation of the operational objective functions.

\begin{tabular}{lccccc}
\hline \multicolumn{1}{c}{ Scenario of Operation } & $\begin{array}{c}\mathrm{HP}_{\text {mean }} \\
\mathrm{GWh} / \mathrm{y}\end{array}$ & $\begin{array}{c}\mathrm{PF} \\
\%\end{array}$ & $\begin{array}{c}\text { Deficit }_{\text {mean }} \\
\mathrm{km}^{3} / \mathrm{y}\end{array}$ & $\begin{array}{c}\mathrm{FE} \\
\mathrm{GWh} / \text { month }\end{array}$ & EDP $_{\text {max }}$ \\
\hline HP maximization & 15907 & 30 & 1.73 & 9 & 1 \\
Minimized deficit of $H P_{\text {max }}$ & 15880 & 30 & 1.66 & 7 & 1.1 \\
Release maximization & 12127 & 23 & 0.85 & 2 & 1 \\
Minimized deficit of $Q_{\text {max }}$ & 12817 & 24 & 1.15 & 328 & 1.2 \\
Minimized HP variance & 13605 & 26 & 1.39 & 1057 & 3.1 \\
Minimized Q variance & 13865 & 26 & 1.40 & 973 & 3.2 \\
Firm energy maximization & 14652 & 28 & 1.56 & 1075 & 3.1 \\
\hline
\end{tabular}

\subsection{GERD Operation Using Maximization of}

\section{Firm Energy Objective Function}

Droughts are prolonged periods with flow less than the long term mean Blue Nile flow and are thus critical periods for $F E_{k}$ calculation. Drought duration, frequency, and accumulated water deficit are reflected in $F E_{k}$ magnitude. A Biblical reference tells us "seven years of great abundance are coming throughout the land of Egypt, but seven years of famine will follow them" (Genesis 41, 29-30). From ancient times, the Nile Basin has tended to exhibit the Hurst phenomenon: persistence of long periods of droughts followed by long periods of floods. The model bottleneck is the longest historical continuous period of drought (1978-1987). The monthly value of $F E_{k}$ was iterated until it reached its maximum possible value.

\section{Reservoir Water Level}

GERD tends to operate at high reservoir water levels to maximize its hydropower production. Spillages, with a total volume of 8.1 $\mathrm{km}^{3}$, occur in 20 months out of the $100 \mathrm{y}$ of operation. The average reservoir water level is $629 \mathrm{~m}$. Figure 2 shows the variation in GERD reservoir water level over the 100 y time series.

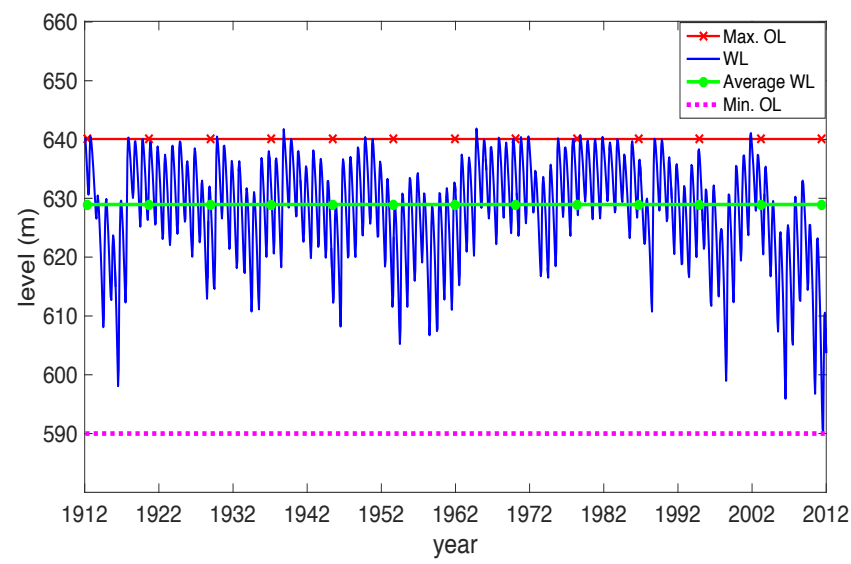

Figure 2 Monthly GERD reservoir water level (WL) and operational levels (OL).

\section{Blue Nile Flow}

GERD operation smooths the natural pattern of the Blue Nile flow to downstream countries as shown in Figure 3. However, the results show an average annual permanent flow reduction of $1.56 \mathrm{~km}^{3}$ due to evaporation losses in the GERD reservoir. Figure 4 shows the annual and average inflows at GERD compared to dam outflows.

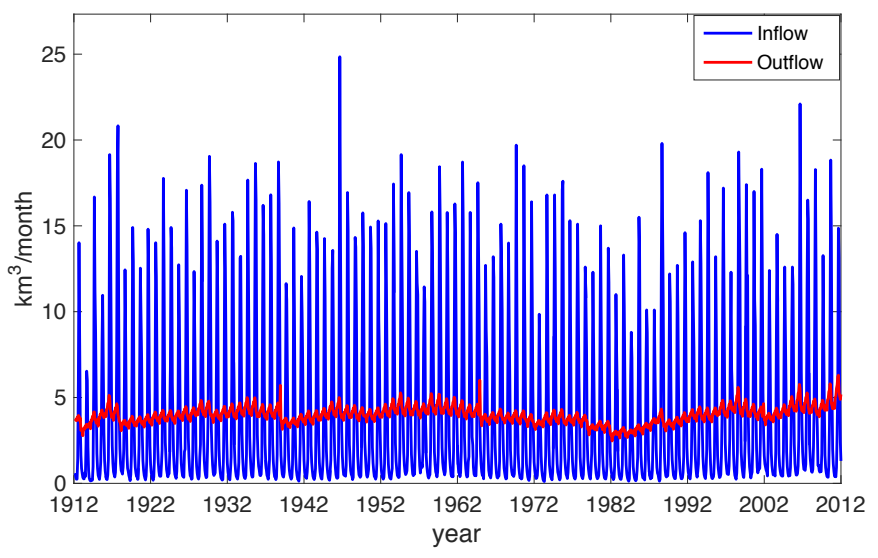

Figure 3 Monthly inflow and outflow of GERD.

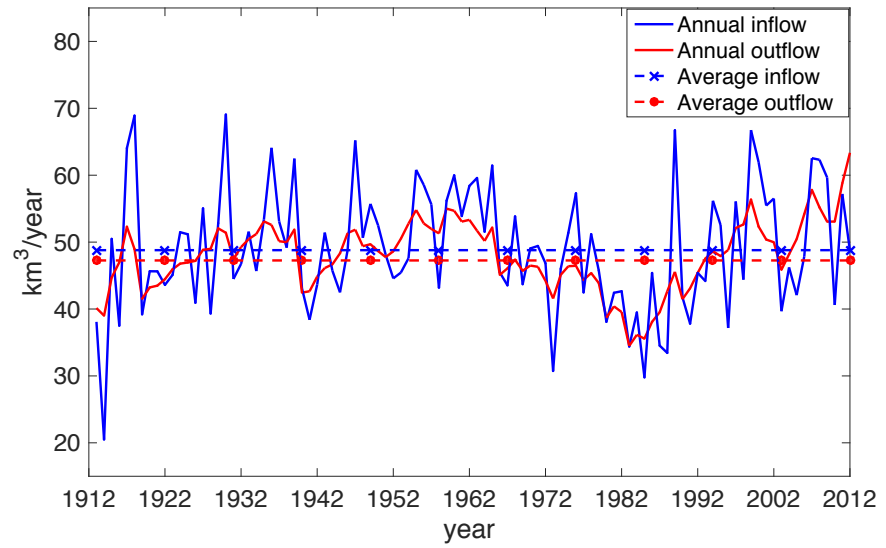

Figure 4 Annual inflow and outflow of GERD.

Blue Nile flow reduction would decrease the HAD average operating level, which would cause a permanent reduction in HAD hydropower generation. The reduced HAD operating levels would in turn reduce the HAD evaporation losses. However, the Blue Nile regulated flow will increase operating levels of the Sudanese dams throughout the year and therefore increase any accompanying reservoir evaporation losses. Thus part of the Nile system losses will be transferred upstream as a consequence of GERD operation.

\section{Hydropower Production}

Figure 5 shows GERD monthly hydropower production over the time series. The results emphasize how the model successfully deals with Blue Nile flow seasonality. GERD firm energy is a minimum production of $1075 \mathrm{GWh} /$ month except during droughts. The average monthly hydropower production of GERD is 1221 GWh and the maximum production is $1362 \mathrm{GWh} /$ month, which represents $\sim 31 \%$ of the installed capacity of the dam. 


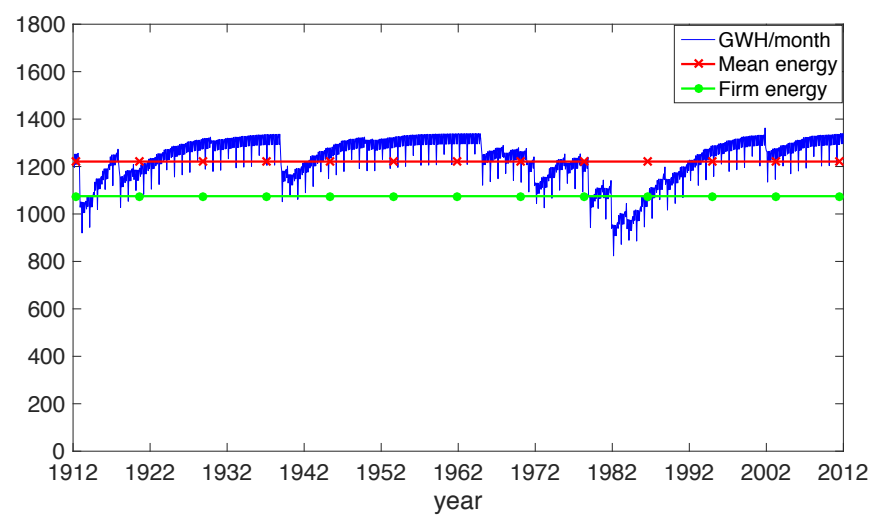

Figure 5 GERD hydropower production.

\section{Extended Drought Periods}

Although GERD outflow would be reduced on average by $3.2 \%$ in the long term, potential downstream impacts result from the initial impoundment of the reservoir, the actual operation strategy, and the refilling of the dam after periods of drought. These impacts could be significant if not carefully managed. Consider the effect on the Nile of the period in the 1980s which was one of the driest periods on the Nile. During that period the natural flow was reduced by approximately $104 \mathrm{~km}^{3}$ over 10 consecutive years. HAD is the most downstream major control structure along the Nile Basin; its live storage $\left(90 \mathrm{~km}^{3}\right)$ was almost depleted at the end of this period. After the $10 \mathrm{y}$ drought, HAD started to recover without water shortage in the downstream water require-ment (given that Sudan abstraction was less than the current abstraction volume). Contrarily, if a similar period were to occur after GERD operation, HAD and GERD will likely deplete their live storage. The question now is how the two dams will be filled and whether a cooperative refilling strategy will be implemented or not. GERD was announced to be built for hydropower generation and in this paper, we investigated the operation of GERD only in stabilizing maximum power production; we do not account for cooperative multi-reservoir management. Before the drought begins, GERD will reduce releases to maintain a high water level and firm energy, while the level of HAD will be dropping due to the decrease in the release from GERD. When the drought starts HAD will be depleted first and downstream demand will experience a water shortage. With the extended downstream drought period, GERD will also be losing water above the minimum level for operating its turbines. When the dry period ends, GERD will start refilling first, which will extend the drought conditions suffered by HAD. The results show that the downstream drought will be extended for 31 years after GERD with a cumulative deficit of 171 $\mathrm{km}^{3}$, as shown in Figure 6. This deficit is due to decrease in river yield during the drought, cumulative extra evaporation loss in the system after GERD, and the refilling volume of GERD.

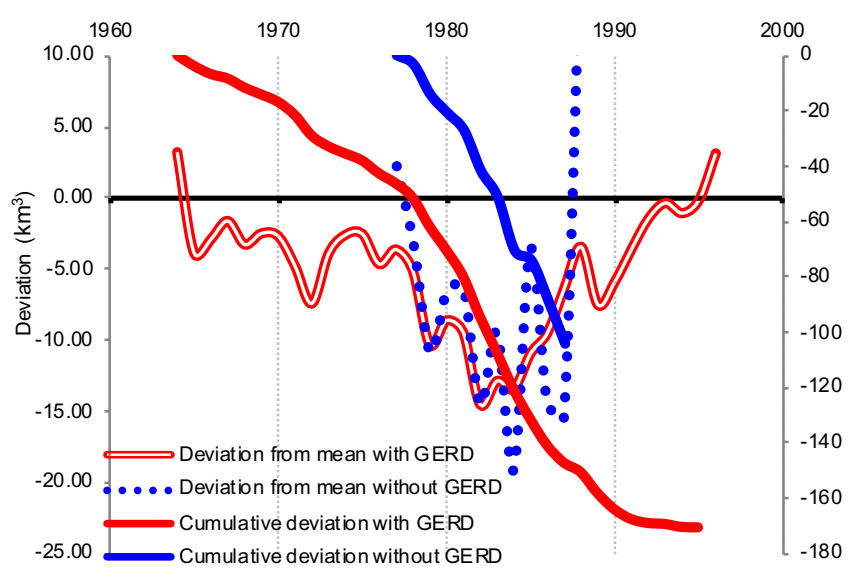

Figure 6 Extended drought period downstream of GERD.

Figure 7 shows the deviation from the long term average flow of the Blue Nile at the GERD site before and after the dam construction. The top plot of Figure 7 shows the difference between the measured inflow at the GERD site and the long term average flow before dam construction, and the lower plot of Figure 7 shows the difference between the release from GERD and the long term average flow based on the optimization model after the dam construction. Comparing the two subplots indicates the following. If GERD operated only for hydropower production, and there was no need to consider downstream conditions, the downstream drought period will increase. This is evidenced by comparing the dry period of 1980s before and after dam construction. Before dam construction (top plot) the period from 1965 to 1995 included several above average cycles, whereas after dam construction the release from GERD in the entire period was below the long term average. This will expose the downstream countries to severe conditions that they have never previously experienced. Finally, GERD had emptied its reservoir storage by the end of the operation period, causing a positive deviation from the mean to maximize hydropower generation and overall firm energy. This would not be case in practice for a lifetime operation.

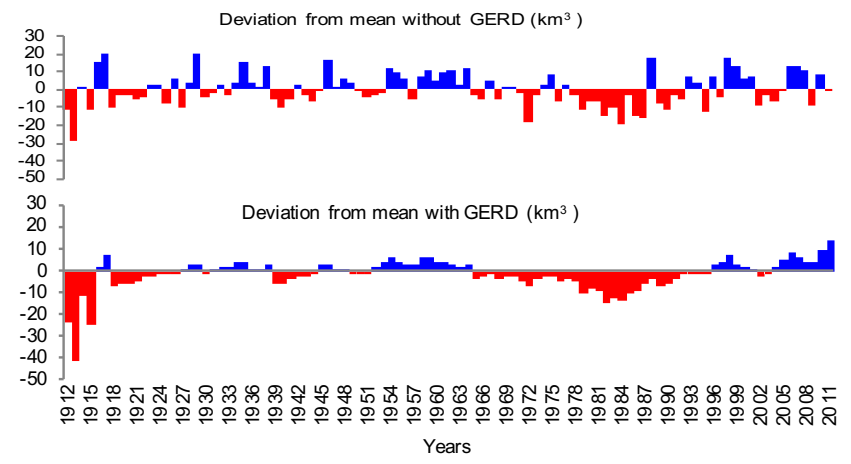

Figure 7 Annual Blue Nile flow deviations from historical mean downstream of GERD. 


\subsection{Impact of GERD Active Storage Capacity}

The model predicted GERD performance under different scenarios of reservoir active storage capacity. Using the same planned dam characteristics and configurations, four scenarios of active capacity were evaluated: $45 \mathrm{~km}^{3}, 35 \mathrm{~km}^{3}, 25 \mathrm{~km}^{3}$ and $15 \mathrm{~km}^{3}$. The firm energy maximization is used as the OF for the GERD optimization operational model.

Decreasing GERD reservoir active storage capacity reduced the impact on downstream countries while maintaining considerable hydropower production. This was due to decreased annual evaporation losses and reducing the downstream drought duration. Figure 8 shows the hydropower production reliability curve for the evaluated scenarios of GERD active capacity. Table 3 gives the results of all scenarios. For a given scenario, the permanent reduction in the Blue Nile flow due to GERD divided by the mean historical inflow is defined as \%PD; the ratio between the mean annual power production relative to the planned dam production is \%HP. For example, the results showed that decreasing GERD live storage by $40 \%$ to reach $35 \mathrm{~km}^{3}$ yields $90 \%$ of the mean annual hydropower production of the planned live capacity of $59 \mathrm{~km}^{3}$ while limiting Blue Nile flow reduction to $2.5 \%$.

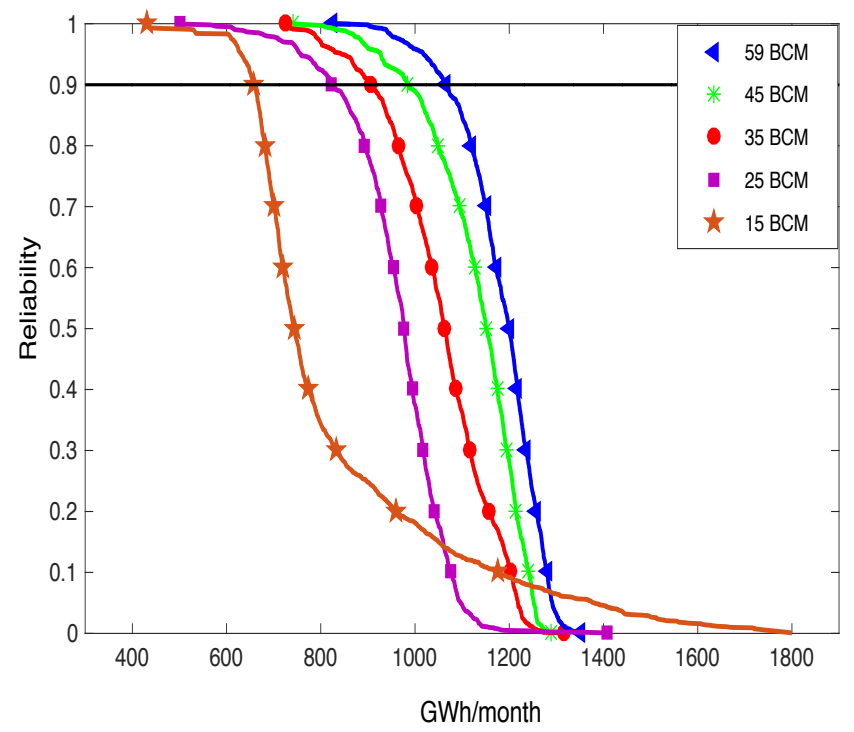

Figure 8 Hydropower production reliability versus GERD active storage capacity.

Table 3 The tradeoff between GERD active storage capacity and its implications.

\begin{tabular}{ccccc}
\hline Active storage $\left(\mathrm{km}^{3}\right)$ & $\mathrm{FE}$ & \%PD & $\mathrm{EDP}_{\max }$ & $\% \mathrm{HP}$ \\
\hline 15 & 662 & 1.9 & 1.08 & 69 \\
25 & 828 & 2.2 & 1.2 & 80 \\
35 & 921 & 2.5 & 2.3 & 90 \\
45 & 998 & 2.8 & 3.1 & 94 \\
59 & 1075 & 3.2 & 3.1 & 100 \\
\hline
\end{tabular}

Limiting the storage capacity of GERD will significantly decrease the adverse effects on downstream countries while maintaining high levels of hydropower benefit. In addition, reducing GERD active capacity to $35 \mathrm{~km}^{3}$ can be done without changing the dam configuration by operating the dam and keeping the gated spillway fully open. This alternative can be adopted even if the construction status or political considerations do not permit other storage reduction actions for the dam.

\section{Conclusions}

Upstream countries have the right to invest in their water resources, but at the same time the possible negative effects on downstream countries must be considered. Since the beginning of GERD construction on the Blue Nile in 2011, no agreement has been reached between the Eastern Nile countries on the critical issues of dam capacity, initial filling policy, and dam operation. This paper presents an optimization operational model for GERD and the implications of different scenarios for dam operation. The objective function of firm energy maximization proved to be reliable in maximizing hydropower production and better regulating the natural flow of the Blue Nile. The mean annual hydropower production of GERD was found to be in the order of $14650 \mathrm{GWh}$ and the firm energy was $12900 \mathrm{GWh} / \mathrm{y}$. The results showed that GERD operation would cause an average $3.2 \%$ reduction in the Blue Nile flow to downstream countries due to evaporation losses from the GERD reservoir. However, the most severe negative effect of GERD on downstream countries, particularly Egypt, occurs during drought periods. Unilateral GERD operation extends the duration of the drought downstream by $\sim 250 \%$ due to the expected refilling period of GERD after a major natural drought. This would cause an extended HAD power station shutdown and a permanent loss of large areas of agricultural lands downstream of GERD. The extended periods of drought would become more frequent due to the seasonality of Blue Nile flow. Most critically, these conditions could occur during and immediately after the initial filling of the dam. The results show that less dam active storage capacity would reduce decreases in the flow of the Blue Nile while maintaining competitively high hydropower production. The findings of this study can help to resolve the related outstanding issues of sizing, initial filling, and operation of GERD.

\section{References}

Abdelazim, N. 2017. An Optimization Operational Model of the Grand Ethiopian Renaissance Dam. Cairo: Cairo University. MSc thesis.

Geressu, R. T. and J. J. Harou. 2015. "Screening Reservoir Systems by Considering the Efficient Trade-offs-Informing Infrastructure Investment Decisions on the Blue Nile.' Environmental Research Letter 10. https://doi.org/10.1088/1748-9326/10/12/125008

Habteyes, B. G., H. A. El-bardisy, S. A. Amer, V. R. Schneider and F. A. Ward. 2015. "Mutually Beneficial and Sustainable Management of Ethiopian and Egyptian Dams in the Nile Basin." 
Journal of Hydrology 529: 1235-46.

https://doi.org/10.1016/j.jhydrol.2015.09.017

Hussein, R. 2015. The Impacts of Ethiopian Renaissance Dam on Egypt and the Role of Conservation Projects and Climate Change. Cairo: Cairo University. MSc thesis.

IPoE (International Panel of Experts). 2013. Grand Ethiopian Renaissance Dam Project (GERDP): IPoE Final Report. Addis Ababa: Government of Ethiopia.

Mulat, A. G. and S. A. Moges. 2014. "Assessment of the Impact of the Grand Ethiopian Renaissance Dam on the Performance of the High Aswan Dam." Journal of Water Resource and Protection 6:583-98.

https:// doi.org/10.4236/jwarp.2014.66057

MWRI (Ministry of Water Resources and Irrigation). 2014. Water Scarcity in Egypt: The Urgent Need for Regional Cooperation among the Nile Basin Countries. Cairo: MWRI.
NBI (Nile Basin Initiative). 2016. Nile Basin Water Resources Atlas. http://www.nilebasin.org

Senosy, M. A. 2015. Stochastic Analysis of the Impact of the Grand Ethiopian Renaissance Dam on High Aswan Dam (HAD). Cairo: Cairo University. MSc thesis.

Shahin, M. 1985. Hydrology of the Nile Basin. Amsterdam: Elsevier Science.

Van der Krogt, W. N. M. and H. J. M. Ogink. 2013. “Development and Application of the Eastern Nile Water Simulation Model and Opportunities for Further Research." In Proceedings of the New Nile Perspectives Conference, Khartoum, Sudan, May 6-7, 2013. 